\title{
Risk Factors for Severe Opioid-Related Adverse Events in a National Cohort of Medical Hospitalizations
}

\author{
Shoshana J. Herzig, MD, MPH $H^{1,2}$, Mihaela S. Stefan, MD ${ }^{3,4}$, Penelope S. Pekow, PhD ${ }^{3,5}$, \\ Meng-Shiou Shieh, $\mathrm{PhD}^{3}$, William Soares, MD, MS ${ }^{3,6}$, Karthik Raghunathan, MD, MPH', \\ and Peter K. Lindenauer, MD, MSc $3,4,8$
}

\begin{abstract}
'Department of Medicine, Division of General Medicine, Beth Israel Deaconess Medical Center, Boston, MA, USA; ${ }^{2} \mathrm{Harvard}$ Medical School, Boston, MA, USA; ${ }^{3}$ Institute for Healthcare Delivery and Population Science, University of Massachusetts Medical School-Baystate, Springfield, MA, USA; ${ }^{4}$ Department of Medicine, University of Massachusetts Medical School-Baystate, Springfield, MA, USA; ${ }^{5}$ School of Public Health and Health Sciences, University of Massachusetts-Amherst, Amherst, MA, USA; ${ }^{\circ}$ Department of Emergency Medicine, University of Massachusetts Medical School-Baystate, Springfield, MA, USA; ${ }^{7}$ Anesthesiology Service, Durham VA Medical Center, Duke University Medical Center, Durham, NC, USA; ${ }^{8}$ Department of Population and Quantitative Health Sciences, University of Massachusetts Medical School, Worcester, MA, USA.
\end{abstract}

BACKGROUND: Opioids are a leading cause of adverse drug events in the hospital. Guidelines recommend that physicians assess the risks of opioids and discuss them with patients when considering opioid use. There are no studies examining patient- and prescribing-related risk factors for opioid-related adverse drug events (ORADEs) in hospitalized medical patients.

OBJECTIVE: To identify independent risk factors for severe ORADEs in hospitalized medical patients.

DESIGN: Retrospective cohort study.

PATIENTS: Medical patients hospitalized at US, non-federal, and acute care facilities, with at least one pharmacy charge for an opioid during hospitalization. We excluded patients with metastatic malignancy, hospice, or palliative care billing codes.

MAIN MEASURES: We used Cox proportional hazards modeling to identify risk factors for severe ORADEs, defined by a pharmacy charge for naloxone. Candidate risk factors were chosen a priori, based on clinical grounds and prior literature.

KEY RESULTS: Among 731,208 hospitalizations (median age $60,56.5 \%$ female), a severe ORADE occurred in 2727 (0.4\%). Independent risk factors included patient characteristics (advanced age, female gender), comorbidities (congestive heart failure, opioid abuse/dependence, non-opioid drug abuse/dependence, psychosis, depression, obstructive sleep apnea), organ failures on admission (respiratory failure, shock/hypotension, renal failure, hepatic failure, acidosis, and neurologic failure), medication co-administrations (antipsychotics and short-acting benzodiazepines), and characteristics of the opioid prescriptions themselves (total dose for the day, parenteral route of administration, and receipt of multiple types of opioids in a day). Although a risk prediction model derived from these factors performed well on stratified $k$ -

This work has not been previouslu presented

Electronic supplementary material The online version of this article (https://doi.org/10.1007/s11606-019-05490-w) contains supplementary material. which is available to authorized users.

Received February 19, 2019

Revised August 12, 2019

Accepted September 25, 2019

Published online November 14, 2019 fold cross-validation (average $c$-statistics 0.68-0.71), the low incidence of the outcome limited the positive predictive value of the risk score.

CONCLUSIONS: In this national cohort of medical patients, we identified several risk factors for ORADEs that can be used to inform physician decision-making, conversations with patients about risk, and development and targeting of harm reduction strategies for at-risk populations.

KEY WORDS: opioids; naloxone; adverse effects of opioids; adverse drug events; risk scores; hospitalization.

J Gen Intern Med 35(2):538-45 DOI: $10.1007 / \mathrm{s} 11606-019-05490-w$ (C) Society of General Internal Medicine 2019

\section{INTRODUCTION}

Opioid medications are one of the leading causes of adverse drug events in hospitalized patients in the USA. ${ }^{1,2}$ Severe opioid-related adverse drug events (ORADEs), including somnolence, respiratory depression, and cardiopulmonary arrest, have been associated with increased length of stay, higher cost of care, increased risk of 30-day readmission, and increased in-hospital mortality. ${ }^{3-9}$

Identifying risk factors for ORADEs is important because more than half of all medical and surgical patients receive an opioid medication while hospitalized. ${ }^{3-5}$ Risk factors identified in the surgical and outpatient literature include patientrelated factors, like age, ${ }^{4-6,10-12}$ male sex, ${ }^{4,6}$ obesity, ${ }^{4,} 6$ chronic obstructive pulmonary disease (COPD), ${ }^{5,13}$ obstructive sleep apnea (OSA), ${ }^{14-16}$ reduced renal or hepatic function, ${ }^{17}$ pre-surgery opioid use, ${ }^{4,5}$ mental health comorbidities, ${ }^{18}$ prior substance use disorders, ${ }^{18,}{ }^{19}$ and higher comorbidity burden, $4,5,11$ as well as prescribing-related factors, such as high doses $6,8,14,15,20,21$ and co-administration of other sedating medications. ${ }^{13,14,} 20$ Although studies have evaluated risk factors for ORADEs in surgical patients, we are aware of just two prior studies examining risk factors for 
ORADEs in hospitalized medical patients. ${ }^{13,22}$ Patients hospitalized for medical reasons are fundamentally different from those hospitalized for surgical reasons with respect to demographics, comorbidities, the conditions prompting opioid use, and even the characteristics of the opioid prescriptions themselves (e.g., type, route, frequency). Of the prior studies examining risk factors in medical hospitalizations, one was limited by small sample size, while the other was limited by reliance on non-specific administrative billing codes for cardiopulmonary arrest to define the outcome, and lack of information on prescribing-related risk factors, such as opioid dose or route of administration. ${ }^{22}$

Developing a better understanding of ORADE risk factors in hospitalized medical patients is crucial to inform the risk-tobenefit calculations and discussions with patients widely advocated by recent guidelines on safe opioid prescribing ${ }^{23,24}$ and to appropriately target interventions to mitigate risk. ${ }^{25,26}$ In this study, we sought to identify independent risk factors for severe ORADEs in a large, national cohort of medically hospitalized patients. We hypothesized that both patient characteristics and characteristics of the opioid administrations themselves (e.g., dose, route) would be associated with severe ORADEs.

\section{METHODS}

\section{Setting and Patients}

We conducted a retrospective cohort study using data from all US, non-federal, and acute care facilities contributing to the Premier database (Premier Healthcare Solutions, Inc., Charlotte, NC, USA). This database, created to measure healthcare utilization and quality of care, is drawn from voluntarily participating hospitals and contains data on approximately $20 \%$ of hospital discharges nationwide. ${ }^{27}$ Participating hospitals are similar in geographic distribution and metropolitan status to hospitals nationwide, although large teaching hospitals, and hospitals in the Southern USA are overrepresented. The database contains patient demographics, International Classification of Diseases, Tenth Revision, Clinical Modification (ICD-10-CM) codes, and a date-stamped log of all charges, including medications. Because the data do not contain identifiable information, the Baystate Medical Center Institutional Review Board determined that this study did not constitute human subjects research.

All medical hospitalizations for patients at least 18 years of age at participating hospitals from January 1, 2016 to December 31, 2016 with at least one pharmacy charge for an opioid medication were eligible for inclusion. We defined a medical hospitalization as one that had a Medicare Severity-Diagnosis Related Group (MS-DRG) flagged as medical and did not have operating room charges. Because the goals of opioid therapy in the setting of cancer-related pain or palliative care are unique, we excluded hospitalizations of patients with metastatic malignancy (defined by presence of an ICD-10-
$C M$ code indicative of metastatic malignancy as defined by the Healthcare Cost and Utilization Project (HCUP) comorbidity measures) ${ }^{28}$ and patients admitted from hospice (where admission source is "transfer from hospice") or with a palliative care code (ICD-10-CM Z51.5) classified as present on admission. We also excluded hospitalizations with missing information on opioid dose or extreme opioid doses, defined as presence of any hospitalization days with a total oral morphine equivalent dose $>99$ th percentile $(660 \mathrm{mg}$ in oral morphine equivalents), since these are likely to represent erroneous data entries. We excluded hospitalizations with a naloxone charge prior to the first opioid charge and those with a naloxone charge more than 1 day from the last opioid charge since these circumstances make the event less likely to be attributable to in-hospital opioid use. Finally, we excluded hospitalizations with unknown gender.

\section{Opioid Exposure}

We defined opioid exposure as presence of any pharmacy charge where the drug class was defined as "opioids" in the Premier dataset (codeine, buprenorphine, butorphanol, fentanyl, hydrocodone, hydromorphone, meperidine, methadone, morphine, nalbuphine, oxycodone, oxymorphone, pentazocine, tapentadol, tramadol).

\section{Severe ORADEs}

We defined occurrence of a severe ORADE by presence of a charge for naloxone, since naloxone is almost exclusively used for treatment of a suspected severe opioid-related adverse event, including sedation or respiratory depression. In addition, naloxone is one of the Institute for Healthcare Improvement's (IHI) "triggers" for identifying adverse drug events. ${ }^{29}$ A study assessing the positive predictive value of naloxone for adverse drug events in adult patients in a hospital setting found a high positive predictive value of $91 \% .^{30}$

\section{Candidate Risk Factors}

We chose candidate risk factors based on clinical grounds and previously demonstrated associations in other patient populations and settings of care, hypothesizing that each would be associated with severe ORADEs. They included the following:

- Demographics: age, gender

- Comorbidities: congestive heart failure, chronic pulmonary disease, obesity, alcohol abuse, drug abuse (separated into two variables representing opioid abuse/ dependence and non-opioid drug abuse/dependence), psychoses, and depression, all defined by the HCUP comorbidity measures, ${ }^{28}$ and obstructive sleep apnea and dementia, defined using ICD-9/10-CM codes in any position, listed in Online Appendix Table 1

- Organ failure present on admission: hematological, respiratory, cardiovascular (shock/hypotension), renal, 
hepatic, acidosis, and neurologic, defined and operationalized in prior analyses using $I C D-9-C M$ codes flagged as present on admission, ${ }^{31}$ which we converted to $I C D-10$ $C M$ codes using a publicly available conversion tool from the Centers for Medicare and Medicaid Services ${ }^{32}$ (Online Appendix Table 1)

- Medication co-administrations: benzodiazepines (grouped as short- and long-acting), and antipsychotics

- Probable opioid-maintenance therapy: defined by presence of charges within the first 2 days of hospitalization for once daily methadone or any buprenorphine

- Probable pre-existing long-term opioid therapy: defined by presence of charges within the first 2 days of hospitalization for any long-acting opioid except once daily methadone (which would count as "probable opioid-maintenance therapy")

- Prescription characteristics: total opioid dose during calendar day in oral morphine equivalents (OME), route of administration (oral/rectal, parenteral/transdermal), and number of types of opioids during calendar day (single or multiple, defined by presence of at least 2 different opioid drugs [e.g., morphine and hydromorphone], or different formulations of the same drug [e.g., long-acting and short-acting morphine])

\section{Statistical Analysis}

We report cohort characteristics and outcomes stratified by presence or absence of a severe opioid-related ADE and calculated standardized mean differences (SMD) to gauge differences between groups, with SMD $>0.10$ considered meaningful. ${ }^{33}$

We used Cox proportional hazards modeling to identify independent predictors of severe ORADEs. We chose this approach to account for the time-varying nature of several of our candidate risk factors, including medication coadministrations and opioid prescription characteristics, which can change daily. We defined time zero as the day of the first opioid administration, excluding from the analysis any time prior to opioid administration since patients are not at risk for an in-hospital ORADE until they are exposed in the hospital. Observations were censored at hospital discharge or 15 days after the first opioid administration to avoid inclusion of outlier time, which would not be representative of the typical medical patient. We hypothesized that the relationship between opioid dose and severe ORADEs would be impacted by pre-hospitalization opioid use, so assessed for effect modification of dose by prehospitalization long-term opioid use.

To increase the usability of the model, we took steps to make it parsimonious. First, we combined candidate risk factors that were clinically similar, had a similar magnitude of effect, and where a test of contrast yielded a $p$ value $>0.05$. On this basis, we combined probable opioid-maintenance therapy and probable pre-existing long-term opioid therapy into a single variable representing probable pre-hospitalization long-term opioid use. We also combined psychoses and depression into a single variable representing psychoses/depression. Finally, we retained only those variables with $p<0.05$ in the final model.

We used stratified $k$-fold cross-validation to assess the internal validity of our model. ${ }^{34}$ Using this methodology, we divided the data into 5 segments ("folds") stratified by outcome to achieve approximately the same rate of outcome in each stratum. We then refit the model we developed on the full cohort in 4 of the "folds" ( $80 \%$ data) and validated it on the remaining fold ( $20 \%$ data). This was performed a total of 5 times, leaving out a different "fold" each time. We computed $c$-statistics as a measure of model fit for each validation "fold" and computed the mean and standard deviation of the five $c$ statistics obtained in this manner.

We used our final model to develop a point scoring system for daily risk calculation. ${ }^{35}$ To do so, we first ranked predictor variables based on their regression coefficients. We then set the largest beta coefficient to a point score of 10 and sequentially assigned point values for other predictors based on their relative coefficients. We grouped age into discrete categories and rounded to whole numbers to simplify computation of the score. We calculated test characteristics based on different point thresholds and used these values to derive receiver operating curves (ROC) by day for the first 3 days.

All analyses were carried out using the SAS software, version 9.4, Cary, NC.

\section{RESULTS}

\section{Cohort Characteristics}

There were 5,240,538 adult hospitalizations at 516 participating hospitals from January 1, 2016 to December 31, 2016. After exclusions (Online Appendix Figure 1), 731,208 medical hospitalizations were included in our analytic cohort (see Table 1 for cohort characteristics). The median age was 60 , and females represented $56.5 \%$ of the cohort. The most common primary diagnoses overall, based on the Agency for Healthcare Research and Quality Clinical Classification System, ${ }^{36}$ were septicemia (7.1\%), skin and subcutaneous tissue infections $(4.2 \%)$, and congestive heart failure (3.5\%). The most common diagnoses among hospitalizations with a severe ORADE were septicemia (9.2\%), cardiac dysrhythmias (5.2\%), and poisoning by other medications and drugs $(5.2 \%)$. The most commonly used opioid was morphine $(323,956,44.3 \%)$, followed by hydrocodone $(221,447$, $30.3 \%)$ and oxycodone $(196,694,26.9 \%)$.

\section{Unadjusted Associations Between Candidate Risk Factors and Severe ORADEs}

A severe ORADE occurred in $2727(0.4 \%)$ hospitalizations, with 1635 (60\%) occurring on day 1 of opioid exposure, 532 
Table 1 Cohort Characteristics and Outcomes Stratified by Presence or Absence of a Severe Opioid Related Adverse Drug Event (ORADE; $N=$ 731,208)

\begin{tabular}{|c|c|c|c|}
\hline \multirow[t]{2}{*}{ Characteristics } & \multirow{2}{*}{$\begin{array}{l}\text { No ORADE } \\
n=728,481(99.6 \%)\end{array}$} & \multirow{2}{*}{$\begin{array}{l}\text { Severe ORADE } \\
n=2727(0.4 \%)\end{array}$} & \multirow[t]{2}{*}{ SMD } \\
\hline & & & \\
\hline \multicolumn{4}{|l|}{ Demographics } \\
\hline Age in years - median (Q1-Q3) & $60(46-73)$ & $61(49-74)$ & 0.06 \\
\hline Female $-n(\%)$ & $411,600(56.5)$ & $1637(60.0)$ & 0.07 \\
\hline \multicolumn{4}{|l|}{ Comorbidities $-n(\%)$} \\
\hline Congestive heart failure & $137,980(18.9)$ & $644(23.6)$ & 0.11 \\
\hline Chronic pulmonary disease & $208,622(28.6)$ & $903(33.1)$ & 0.10 \\
\hline Obesity & $129,406(17.8)$ & $522(19.1)$ & 0.04 \\
\hline Alcohol abuse & $51,509(7.1)$ & $216(7.9)$ & 0.03 \\
\hline Opioid abuse/dependence & $26,115(3.6)$ & $353(12.9)$ & 0.34 \\
\hline Non-opioid drug abuse/dependence & $40,468(5.6)$ & $260(9.5)$ & 0.15 \\
\hline Psychoses & $39,467(5.4)$ & $244(8.9)$ & 0.14 \\
\hline Depression & $119,503(16.4)$ & $623(22.8)$ & 0.16 \\
\hline Obstructive sleep apnea & $68,010(9.3)$ & $330(12.1)$ & 0.09 \\
\hline Dementia & $45,555(6.3)$ & $215(7.9)$ & 0.06 \\
\hline \multicolumn{4}{|l|}{ Organ failure present on admission- $n(\%)$} \\
\hline Hematological $^{\dagger}$ & $35,704(4.9)$ & $162(5.9)$ & 0.05 \\
\hline Respiratory & $8177(1.1)$ & $69(2.5)$ & 0.11 \\
\hline Cardiovascular (shock/hypotension) & $31,480(4.3)$ & $304(11.1)$ & 0.26 \\
\hline Renal (acute) & $105,168(14.4)$ & $560(20.5)$ & 0.16 \\
\hline Hepatic & $5695(0.8)$ & $49(1.8)$ & 0.09 \\
\hline Acidosis & $32,722(4.5)$ & $217(8.0)$ & 0.14 \\
\hline Neurologic & $26,498(3.6)$ & 325 (11.9) & 0.31 \\
\hline \multicolumn{4}{|l|}{ Medication co-administrations ${ }^{\S}-n(\%)$} \\
\hline Long-acting benzodiazepine & $36,267(5.0)$ & $128(4.7)$ & 0.01 \\
\hline Short-acting benzodiazepine & $245,065(33.6)$ & 1132 (41.5) & 0.16 \\
\hline Antipsychotic & $59,692(8.2)$ & $300(11.0)$ & 0.10 \\
\hline Probable pre-existing long-term opioid therapy $-n(\%)$ & $36,705(5.0)$ & $320(11.70)$ & 0.24 \\
\hline Probable opioid-maintenance therapy $-n(\%)$ & $10,170(1.4)$ & $85(3.1)$ & 0.12 \\
\hline \multicolumn{4}{|l|}{ Opioid prescription characteristics } \\
\hline $\begin{array}{l}\text { Total opioid dose per calendar day in mg oral morphine equivalents - mean } \\
\text { (median, Q1-Q3) }\end{array}$ & $39(19,8-43)$ & $61(30,15-72)$ & 0.30 \\
\hline Oral/rectal ${ }^{\S}-n(\%)$ & $501,243(68.8)$ & $1539(56.4)$ & 0.26 \\
\hline Parenteral $/$ transdermal ${ }^{\S}-n(\%)$ & $482,832(66.3)$ & $1955(71.7)$ & 0.19 \\
\hline Multiple opioid types in single day $-n(\%)$ & $269,849(37.0)$ & $983(36.0)$ & 0.02 \\
\hline \multicolumn{4}{|l|}{ Outcomes } \\
\hline Length of hospitalization in days - mean (median, Q1-Q3) & $3.6(3,2-4)$ & $4.4(3,2-6)$ & 0.23 \\
\hline Total charges - mean (median, Q1-Q3) & $\begin{array}{l}28,548(22,358,14,395- \\
34,869)\end{array}$ & $\begin{array}{l}37,240(28,970,17,843- \\
45,603)\end{array}$ & 0.31 \\
\hline Readmission within 30 days $-n(\%)$ & $79,826(11.0)$ & $335(12.3)$ & 0.04 \\
\hline In-hospital mortality $-n(\%)$ & $8136(1.1)$ & $168(6.2)$ & 0.27 \\
\hline
\end{tabular}

SMD standardized mean difference, $Q$ quartile

† Includes platelet and/or coagulation defects (see Online Appendix Table 1 for specific ICD-10-CM codes)

$\mp$ Includes delirium/encephalopathy, psychiatric disorders due to underlying medical illness, anoxic brain injury, and altered level of consciousness (see Online Appendix Table 1 for specific ICD-10-CM codes)

${ }^{\S}$ At any point during the hospitalization

"Includes administration of more than one type of opioid (i.e., morphine and hydromorphone) and/or different formulations of the same opioid (i.e., short-acting and long-acting morphine)

(20\%) on day 2 , and $230(8 \%)$ on day 3. Compared to hospitalizations without a severe ORADE, hospitalizations with a severe ORADE had higher rates of each of the HCUP-defined comorbidities, notably opioid abuse/ dependence $(3.6 \%$ vs $12.9 \%)$ and depression $(16.4 \%$ vs $22.8 \%$ ), higher rates of in-hospital benzodiazepine (36.1\% vs $44.7 \%)$ and antipsychotic use (8.2\% vs $11.0 \%)$, greater total daily opioid doses on average ( 39 vs $61 \mathrm{mg}$ OME), and a greater incidence of parenteral opioid administration $(65.4 \%$ vs $70.0 \%$; Table 1 ).

\section{Adjusted Associations Between Candidate Risk Factors and Severe ORADEs}

In multivariable Cox proportional hazards modeling, we identified several significant predictors of a severe ORADE (Table 2), the strongest of which were opioid abuse/dependence (HR 2.8, 95\% CI 2.4-3.1), cardiovascular organ failure (shock/ hypotension) present on admission (HR 2.2, 1.9-2.5), neurologic organ failure present on admission (HR 2.8, 2.4-3.1), and receipt of more than one type of opioid in the same day (HR 2.1, 1.5$2.7)$. The model performed well on stratified $k$-fold cross-validation, with average $c$-statistics of $0.68-0.71$ for all derivation and validation "folds" (Online Appendix Table 2).

\section{Severe ORADE Risk Score}

The scoring system derived from the associated model coefficients is presented in Table 3. Hospitalizations with a severe ORADE had greater mean point scores than hospitalizations without a severe ORADE on all days examined (Online Appendix Table 3). The relationship between risk score on day 
Table 2 Adjusted Association Between Characteristics and Severe Opioid-Related Adverse Drug Events in the Final Model $(n=731,208)$

\begin{tabular}{|c|c|c|c|}
\hline Characteristics & $\begin{array}{l}\text { Beta } \\
\text { coefficient }\end{array}$ & $\begin{array}{l}\text { Hazard } \\
\text { ratio }\end{array}$ & $95 \% \mathrm{CI}$ \\
\hline \multicolumn{4}{|l|}{ Demographics } \\
\hline $\begin{array}{l}\text { Age in years (per } 10 \\
\text { years) }\end{array}$ & 0.04 & 1.04 & $1.01-1.06$ \\
\hline Female & 0.17 & 1.2 & $1.1-1.3$ \\
\hline \multicolumn{4}{|l|}{ Comorbidities } \\
\hline Congestive heart failure & 0.20 & 1.2 & $1.1-1.3$ \\
\hline Opioid abuse/dependence & 1.02 & 2.8 & $2.4-3.1$ \\
\hline $\begin{array}{l}\text { Non-opioid drug abuse/ } \\
\text { dependence }\end{array}$ & 0.36 & 1.4 & $1.2-1.6$ \\
\hline Psychoses/depression & 0.20 & 1.2 & $1.1-1.3$ \\
\hline Obstructive sleep apnea & 0.24 & 1.3 & $1.1-1.4$ \\
\hline \multicolumn{4}{|c|}{ Organ failure present on admission } \\
\hline Respiratory & 0.52 & 1.7 & $1.3-2.1$ \\
\hline $\begin{array}{l}\text { Cardiovascular (shock/ } \\
\text { hypotension) }\end{array}$ & 0.80 & 2.2 & $1.9-2.5$ \\
\hline Renal & 0.20 & 1.2 & $1.1-1.3$ \\
\hline Hepatic & 0.43 & 1.5 & $1.1-2.0$ \\
\hline Acidosis & 0.26 & 1.3 & $1.1-1.5$ \\
\hline Neurologic* & 1.02 & 2.8 & $2.4-3.1$ \\
\hline \multicolumn{4}{|c|}{ Medication co-administrations } \\
\hline $\begin{array}{l}\text { Short-acting benzodiaze- } \\
\text { pine }\end{array}$ & 0.58 & 1.8 & $1.6-1.9$ \\
\hline Antipsychotic & 0.20 & 1.2 & $1.1-1.4$ \\
\hline \multicolumn{4}{|c|}{ No pre-hospitalization long-term opioid use } \\
\hline $\begin{array}{l}\text { Total opioid dose on } \\
\text { calendar day in } 10 \mathrm{mg} \text { oral } \\
\text { morphine equivalents }\end{array}$ & 0.01 & 1.0 & $1.0-1.0$ \\
\hline \multicolumn{4}{|c|}{ Probable pre-hospitalization long-term opioid use } \\
\hline $\begin{array}{l}\text { Total opioid dose on } \\
\text { calendar day in } 10 \mathrm{mg} \text { oral } \\
\text { morphine equivalents }\end{array}$ & 0.83 & 2.3 & $1.9-2.7$ \\
\hline \multicolumn{4}{|c|}{ Opioid prescription characteristics } \\
\hline Oral/rectal & -0.31 & 0.7 & $0.6-0.9$ \\
\hline Parenteral/Transdermal & 0.24 & 1.3 & $1.1-1.5$ \\
\hline $\begin{array}{l}\text { One opioid type on } \\
\text { calendar day }\end{array}$ & 0.59 & 1.8 & $1.4-2.2$ \\
\hline $\begin{array}{l}\text { Multiple opioid types on } \\
\text { calendar day }\end{array}$ & 0.74 & 2.1 & $1.5-2.7$ \\
\hline
\end{tabular}

CI confidence interval

*Includes delirium/encephalopathy, psychiatric disorders due to underlying medical illness, anoxic brain injury, altered level of consciousness (see Online Appendix Table 1 for specific ICD-9-CM/ICD-10-CM codes)

${ }^{\dagger}$ Includes administration of more than one type of opioid (i.e., morphine and hydromorphone) and/or different formulations of the same opioid (i.e., short-acting and long-acting morphine)

1 of opioid receipt and the incidence of a severe ORADE is demonstrated in Figure 1a. The proportion of hospitalizations falling into each risk category on hospital day 1 is demonstrated in Figure 1b. Hospitalizations with a score of 12 or more on hospital day 1 had a risk of severe ORADE of $1.1 \%$ and represented $3.8 \%$ of the cohort, while hospitalizations with a score of 15 or more had a risk of severe ORADE of $1.7 \%$ and represented $0.6 \%$ of the cohort.

For each day of opioid receipt, we calculated the sensitivity, specificity, and positive predictive value of different point score thresholds, and used these values to derive ROC curves. Table 4 demonstrates these test characteristics for day 1 of opioid receipt (see Online Appendix Table 4 for test characteristics for days 1, 2, and 3 and Online Appendix Figure 2 for the corresponding ROC curves). Based on these test characteristics, using a point score cutoff of 3 or more to define "high risk" would identify $100 \%$ of the severe ORADEs but would be associated with less than $1 \%$ specificity (i.e., high false-positive rate). Using a point score cutoff of 12 or more would be associated with greater than 95\% specificity but less than $20 \%$ sensitivity for detecting severe ORADEs (i.e., high false-negative rate). The cutoff that simultaneously maximizes sensitivity and specificity is a point score of 8 or more, resulting in $61 \%$ sensitivity, $71 \%$ specificity, and a positive predictive value of $0.46 \%$.

\section{DISCUSSION}

In this large cohort of medical hospitalizations across the USA, we identified several independent predictors of severe ORADEs, including patient characteristics (advanced age, female gender), comorbid diseases (congestive heart failure, opioid abuse/dependence, non-opioid drug abuse/dependence, psychosis, depression, obstructive sleep apnea), organ failures at the time of admission (respiratory failure, shock/hypotension, renal failure, hepatic failure, acidosis, and neurologic failure), medication co-administrations (antipsychotics and short-acting benzodiazepines), and characteristics of the opioid prescriptions themselves (total dose for the day, parenteral

Table 3 Scoring System for Severe Opioid-Related Adverse Drug Events

\begin{tabular}{ll}
\hline \hline Risk factor & Points \\
\hline Age 30-74 & 1 \\
Age 75+ & 2 \\
Female & 1 \\
Congestive heart failure & 1 \\
Opioid abuse/dependence & 4 \\
Non-opioid drug abuse/dependence & 1 \\
Psychosis or depression & 1 \\
Obstructive sleep apnea & 1 \\
Respiratory failure present on & 2 \\
admission & 3 \\
Shock/hypotension present on & 3 \\
admission & 1 \\
Renal failure present on admission & 2 \\
Hepatic failure present on admission & 1 \\
Acidosis present on admission & 4 \\
Neurologic failure present on & \\
admission* & 1 \\
Antipsychotic exposure & 2 \\
Short-acting benzodiazepine exposure & 2 \\
No pre-hospitalization long-term opi- & 0 \\
oid use & \\
$\quad$ Total opioid dose for the day & $0.005^{\dagger}$ dose in mg OME \\
Parenteral only & 4 \\
Oral only & 2 \\
Parenteral and oral & 3 \\
Pre-hospitalization long-term opioid & 4 \\
use Total opioid dose for the day & $-0.01^{\dagger}$ dose in mg OME \\
Parenteral only & $3(+1$ if multiple parenteral \\
Oral only & $1\left(+1\right.$ if multiple oral agents $\left.{ }^{\ddagger}\right)$ \\
Parenteral and oral & 3 \\
\hline
\end{tabular}

*Includes delirium/encephalopathy, psychiatric disorders due to underlying medical illness, anoxic brain injury, altered level of consciousness (see Online Appendix Table 1 for specific ICD-9-CM/ICD-10-CM codes) Score must be updated daily to account for changes in medications *Includes administration of more than one type of opioid (i.e., morphine and hydromorphone), as well as different formulations of the same opioid (i.e., short-acting and long-acting morphine) 

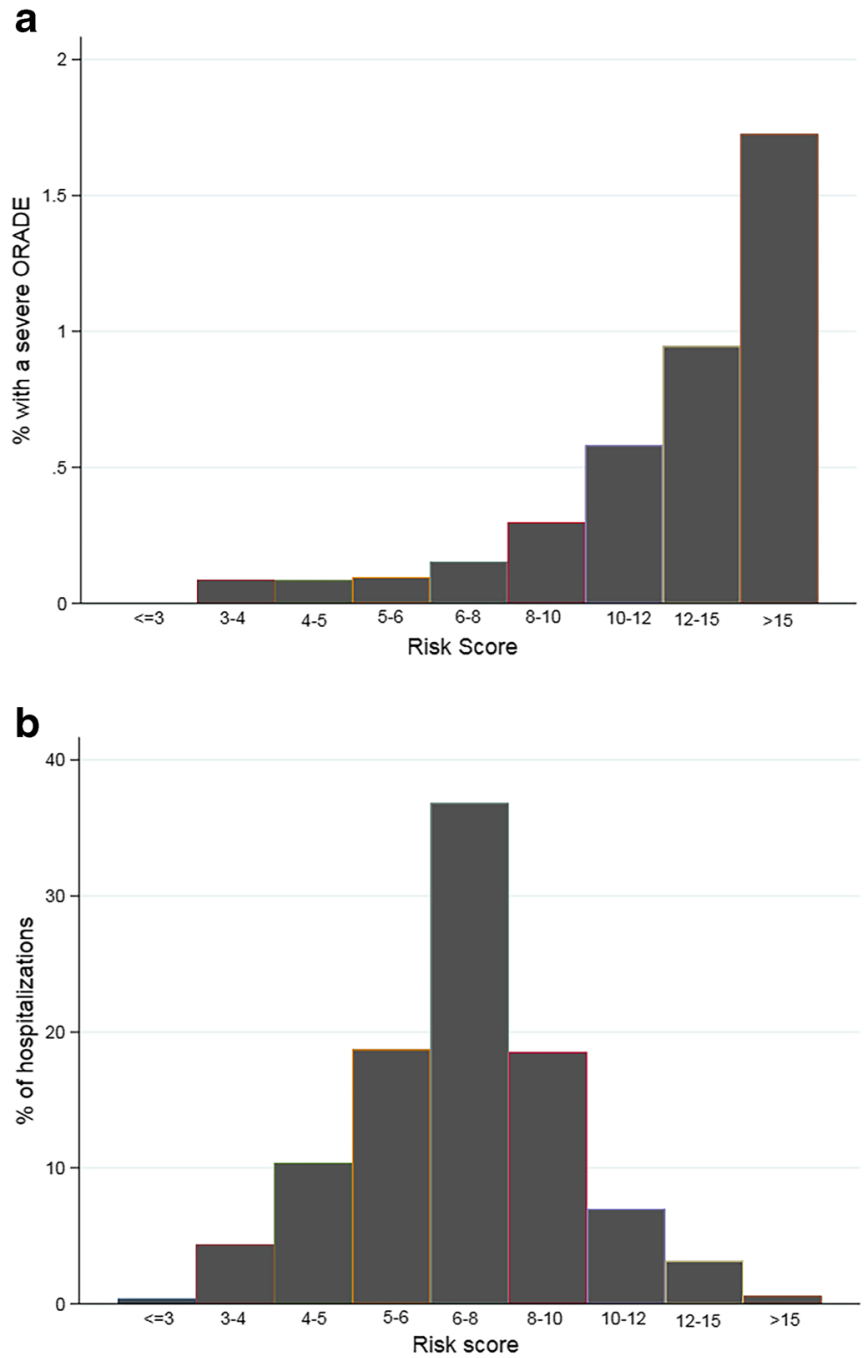

Figure 1 a Bar graph of the percentage of hospitalizations with a severe opioid-related adverse drug event (ORADE) by risk score on day 1 of opioid receipt. b Histogram of the percentage of hospitalizations falling into each risk score category.

route of administration, and receipt of multiple types of opioids in a day). Although a risk prediction model derived from these factors performed well on internal validation, the low incidence of the outcome limited the positive predictive value of the risk score. Awareness of the risk factors themselves, however, may help physicians, hospital systems, and researchers identify patients at higher risk for a severe ORADE, to inform decisions around dosing, sedative co-administration, conversations with patients, and development or deployment of risk-mitigation strategies.

Prior analyses have demonstrated increased risk of cardiopulmonary and respiratory arrest in hospitalized patients exposed to opioids. ${ }^{22,37,38} \mathrm{We}$ are aware of just two prior studies examining risk factors for these outcomes among hospitalized

Table 4 Test Characteristics of Point Scoring System on Day 1 of Opioid Receipt $(n=731,208)$

\begin{tabular}{lllllll}
\hline \hline Point score & Sensitivity & Specificity & PPV & TP & FP & TN \\
\hline$\geq 1$ & 1.00 & 0.00 & $0.22 \%$ & 1635 & 729,505 & 68 \\
$\geq 2$ & 1.00 & 0.00 & $0.22 \%$ & 1635 & 729,438 & 135 \\
$\geq 3$ & 1.00 & 0.00 & $0.22 \%$ & 1635 & 726,821 & 2752 \\
$\geq 4$ & 0.98 & 0.05 & $0.23 \%$ & 1607 & 695,089 & 34,484 \\
$\geq 5$ & 0.94 & 0.15 & $0.25 \%$ & 1543 & 619,420 & 110,153 \\
$\geq 6$ & 0.86 & 0.34 & $0.29 \%$ & 1409 & 482,722 & 246,851 \\
$\geq 7$ & 0.75 & 0.55 & $0.37 \%$ & 1219 & 331,611 & 397 \\
$\geq 8$ & 0.61 & 0.71 & $0.46 \%$ & 998 & 213,721 & 226 \\
$\geq 9$ & 0.48 & 0.82 & $0.60 \%$ & 788 & 131,165 & 515,852 \\
$\geq 10$ & 0.36 & 0.94 & $0.75 \%$ & 595 & 78,335 & 598,408 \\
$\geq 11$ & 0.26 & 0.96 & $1.07 \%$ & 290 & 651,238 \\
$\geq 12$ & 0.18 & & 418 & 46,693 & 847 \\
\hline
\end{tabular}

PPV positive predictive value, TP true positives, $F P$ false positives, $T N$ true negatives, $F N$ false negatives 
medical patients. ${ }^{13,22}$ One was a small, single-center casecontrol analysis that presented only unadjusted associations. ${ }^{13}$ The other also used data from Premier, but differed from ours in that their outcome was defined using ICD-9-CM codes for cardiopulmonary arrest, respiratory arrest, and cardiopulmonary resuscitation, precluding determination of the day of hospitalization upon which the adverse event occurred, and increasing the chance of bias in their observed associations owing to lack of specificity in their outcome definition. They focused on patient-level predictors and did not examine prescribing-related predictors. The risk factors identified in our analysis have good face validity in that they are consistent with those demonstrated by others in surgical patient populations, ${ }^{4,5,8,10,13-15}$ and the outpatient setting. ${ }^{20,} 21,23,39-44$

We chose to focus on severe ORADEs, rather than all ORADEs, for several reasons. First, we did not feel it made clinical sense to group multiple types of ORADEs together (e.g., nausea, constipation, delirium, and opioid-related respiratory depression), since the severity, implications, and predictors of these events are likely to differ. Second, naloxone administration is likely to be more specific to an opioid-related complication relative to other types of adverse events; for example, the causes of delirium are numerous.

Using naloxone administration as a marker of a possible adverse event was originally proposed by Classen et al., ${ }^{45}$ who observed that use of an antidote such as naloxone is one of the most common signals of a subsequently confirmed adverse drug reaction. Naloxone use was subsequently incorporated into the IHI's "adverse drug event trigger tool." 29 A study assessing the positive predictive value of naloxone for adverse drug events in adult patients in a hospital setting found a high positive predictive value of $91 \% .^{30}$ The high specificity of this outcome definition helps to assure unbiased effect estimates, ${ }^{46}$ while simultaneously providing a "date-stamp" for the occurrence of the ORADE, which would not have been available had we used diagnosis codes to define ORADEs.

Despite generally good discriminative ability of our model, the low prevalence of severe ORADEs in this patient population limits the positive predictive value of the scoring system. This poses challenges for application of risk modification strategies, since fewer than $2 \%$ of patients experienced a severe ORADE even in the highest risk category. An intervention would have to be low cost, easily adoptable, and not associated with any detrimental secondary effects to be useful in such a scenario. Electronic health record-based alerts for high risk patients being prescribed opioids is an example of a low cost, flexible intervention that, rather than prohibiting opioid prescribing, could provide important clinical information at the point of care to inform the risk-to-benefit assessment widely advocated by recently released opioid prescribing guidelines. ${ }^{23,}{ }^{24}$ Knowledge of factors that place a patient at heightened risk for a severe ORADE can also be used to facilitate conversations with patients and caregivers about the risks, as recommended in the guidelines. ${ }^{23,} 24$
There are additional limitations of this analysis. The lack of information on pre-admission medication use in the Premier database necessitated use of proxy variables to measure longterm pre-admission opioid medication use, including charges for long-acting opioids in the first 2 days of the hospitalization. This approach would have missed pre-admission use of shortacting opioids, which could be another important predictor of ORADEs. Additionally, our reliance on diagnosis codes to identify some risk factors could have resulted in misclassification and makes prospective operationalization more difficult. Nevertheless, physicians are typically aware of comorbidities and organ failures present at the time of admission.

In conclusion, in this large, national cohort of medical hospitalizations, we identified several risk factors for severe ORADEs, which can be used to inform physician decisionmaking around pain management, conversations with patients or to target at-risk populations for design and testing of interventions to mitigate opioid-associated risk.

Corresponding Author: Shoshana J. Herzig, MD, MPH; Harvard Medical School, Boston, MA, USA (e-mail: sherzig@bidmc.harvard. edu).

Funding Information Dr. Herzig was funded by grant number K23AG042459 from the National Institute on Aging and R01HS026215 from the Agency for Healthcare Research and Quality. Dr. Soares is funded by grant number 1K08DA045933 from the National Institute on Drug Abuse. Dr Lindenauer was funded by grant number K24HL132008 from the National Heart, Lung, and Blood Institute. The funding agencies had no role in the design or conduct of the study; collection, management, analysis, or interpretation of the data; preparation, review, or approval of the manuscript; or decision to submit the manuscript for publication. The manuscript contents are solely the responsibility of the authors and do not necessarily represent the views of the funding organizations.

\section{Compliance with Ethical Standards:}

Conflict of Interest: The authors declare that they do not have a conflict of interest.

\section{REFERENCES}

1. Bates DW, Cullen DJ, Laird N, et al. Incidence of adverse drug events and potential adverse drug events. Implications for prevention. ADE Prevention Study Group. JAMA.1995;274(1):29-34.

2. Lucado J, Paez K, Elixhauser A. Medication-Related Adverse Outcomes in U.S. Hospitals and Emergency Departments, 2008: Statistical Brief \#109. 2006.

3. Herzig SJ, Rothberg MB, Cheung M, Ngo LH, Marcantonio ER. Opioid utilization and opioid-related adverse events in nonsurgical patients in US hospitals. J Hosp Med 2014;9(2):73-81.

4. Kessler ER, Shah M, Gruschkus SK, Raju A. Cost and quality implications of opioid-based postsurgical pain control using administrative claims data from a large health system: opioid-related adverse events and their impact on clinical and economic outcomes. Pharmacotherapy. 2013;33(4):383-391.

5. Minkowitz HS, Gruschkus SK, Shah M, Raju A. Adverse drug events among patients receiving postsurgical opioids in a large health system: risk factors and outcomes. Am J Health Syst Pharm. 2014;71(18):15561565. 
6. Oderda G. Challenges in the management of acute postsurgical pain. Pharmacotherapy. 2012;32(9 Suppl):6S-11S.

7. Oderda GM, Evans RS, Lloyd J, et al. Cost of opioid-related adverse drug events in surgical patients. J Pain Symptom Manag 2003;25(3):276283.

8. Oderda GM, Said Q, Evans RS, et al. Opioid-related adverse drug events in surgical hospitalizations: impact on costs and length of stay. Ann Pharmacother 2007;41(3):400-406.

9. Pizzi LT, Toner R, Foley K, et al. Relationship between potential opioidrelated adverse effects and hospital length of stay in patients receiving opioids after orthopedic surgery. Pharmacotherapy. 2012;32(6):502-514.

10. Cepeda MS, Farrar JT, Baumgarten M, Boston R, Carr DB, Strom BL. Side effects of opioids during short-term administration: effect of age, gender, and race. Clin Pharmacol Ther 2003;74(2): 102-112.

11. Taylor S, Kirton OC, Staff I, Kozol RA. Postoperative day one: a high risk period for respiratory events. Am J Surg 2005; 190(5):752-756.

12. Vestergaard P, Rejnmark L, Mosekilde L. Fracture risk associated with the use of morphine and opiates. J Intern Med 2006;260(1):76-87.

13. Pawasauskas J, Stevens B, Youssef R, Kelley M. Predictors of naloxone use for respiratory depression and oversedation in hospitalized adults. Am J Health Syst Pharm. 2014;71(9):746-750.

14. Weingarten TN, Herasevich V, McGlinch MC, et al. Predictors of delayed postoperative respiratory depression assessed from naloxone administration. Anesth Analg 2015;121(2):422-429.

15. Weingarten TN, Chong EY, Schroeder DR, Sprung J. Predictors and outcomes following naloxone administration during phase I anesthesia recovery. J Anesth 2016;30(1):116-122.

16. Webster LR, Choi Y, Desai H, Webster L, Grant BJ. Sleep-disordered breathing and chronic opioid therapy. Pain Med 2008;9(4):425-432.

17. Brunton LL, ed. Goodman and Gilman's the Pharmacologic Basis of Therapeutics. 9 ed. New York:McGraw-Hill; 1996.

18. Edlund MJ, Steffick D, Hudson T, Harris KM, Sullivan M. Risk factors for clinically recognized opioid abuse and dependence among veterans using opioids for chronic non-cancer pain. Pain. 2007;129(3):355-362

19. Reid MC, Engles-Horton LL, Weber MB, Kerns RD, Rogers EL O'Connor PG. Use of opioid medications for chronic noncancer pain syndromes in primary care. J Gen Intern Med 2002;17(3):173-179.

20. Dasgupta N, Funk MJ, Proescholdbell S, Hirsch A, Ribisl KM, Marshall S. Cohort study of the impact of high-dose opioid analgesics on overdose mortality. Pain Med 2016;17(1):85-98.

21. Bohnert AS, Valenstein M, Bair MJ, et al. Association between opioid prescribing patterns and opioid overdose-related deaths. JAMA. 2011;305(13): 1315-1321.

22. Izrailtyan I, Qiu J, Overdyk FJ, Erslon M, Gan TJ. Risk factors for cardiopulmonary and respiratory arrest in medical and surgical hospital patients on opioid analgesics and sedatives. PLoS One 2018;13(3):e0194553

23. Dowell D, Haegerich TM, Chou R. CDC guideline for prescribing opioids for chronic pain-United States, 2016. JAMA 152016.

24. Herzig SJ, Mosher HJ, Calcaterra SL, Jena AB, Nuckols TK. Improving the safety of opioid use for acute noncancer pain in hospitalized adults: a consensus statement from the Society of Hospital Medicine. J Hosp Med 2018;13(4):263-271.

25. Kooij FO, Klok T, Hollmann MW, Kal JE. Decision support increases guideline adherence for prescribing postoperative nausea and vomiting prophylaxis. Anesth Analg. 2008;106(3):893-898, table of contents.

26. Kooij FO, Vos N, Siebenga P, Klok T, Hollmann MW, Kal JE. Automated reminders decrease postoperative nausea and vomiting incidence in a general surgical population. $\mathrm{Br} \mathrm{J}$ Anaesth 2012;108(6):961-965

27. Pronovost $\mathbf{P}$, Weast B, Schwarz M, et al. Medication reconciliation: a practical tool to reduce the risk of medication errors. J Crit Care 2003; 18(4):201-205.

28. Beta Elixhauser Comorbidity Software for ICD-10-CM Healthcare Cost and Utilization Project (HCUP). March 2018. Agency for Healthcare
Research and Quality, Rockville, MD. Available at: www.hcup-us.ahrq gov/toolssoftware/comorbidityicd10/comorbidity_icd10.jsp. Accessed 26 August 2019.

29. Rozich JD, Haraden CR, Resar RK. Adverse drug event trigger tool: a practical methodology for measuring medication related harm. Qual Saf Health Care 2003;12(3): 194-200.

30. Nwulu U, Nirantharakumar K, Odesanya R, McDowell SE, Coleman JJ. Improvement in the detection of adverse drug events by the use of electronic health and prescription records: an evaluation of two trigger tools. Eur J Clin Pharmacol 2013;69(2):255-259.

31. Martin GS, Mannino DM, Eaton S, Moss M. The epidemiology of sepsis in the United States from 1979 through 2000. N Engl J Med. 2003:348(16):1546-1554.

32. The National Bureau of Economic Research, Centers for Medicare \& Medicaid Services. CMS' ICD-9-CM to and from ICD-10-CM and ICD-10PCS Crosswalk or General Equivalence Mappings. Available at: http:// www.nber.org/data/icd9-icd-10-cm-and-pcs-crosswalk-general-equivalence-mapping.html. Accessed 26 August 2019.

33. Austin PC. Using the standardized difference to compare the prevalence of a binary variable between two groups in observational research. Commun Stat Simul Comput 2009;38(6): 1228-1234.

34. Kohavi R. A study of cross-validation and bootstrap for accuracy estimation and model selection. Proceedings of the 14th International Joint Conference on Artificial Intelligence, Vol. 2, Montreal, 20-25 August 1995, 1137-1145. 1995. Available at: http://ai.stanford.edu/ ronnyk/ accEst.pdf. Accessed 26 August 2019.

35. Iasonos A, Schrag D, Raj GV, Panageas KS. How to build and interpret a nomogram for cancer prognosis. J Clin Oncol. 2008;26(8):1364-1370.

36. Beta Clinical Classifications Software (CCS) for ICD-10-CM/PCS Healthcare Cost and Utilization Project (HCUP). October 2018. Agency for Healthcare Research and Quality, Rockville, MD. Available at: www. hcup-us.ahrq.gov/toolssoftware/ccs10/ccs10.jsp. Accessed 26 August 2019 .

37. Lyons PG, Snyder A, Sokol S, Edelson DP, Mokhlesi B, Churpek MM. Association between opioid and benzodiazepine use and clinical deterioration in ward patients. J Hosp Med 2017;12(6):428-434

38. Overdyk FJ, Dowling O, Marino J, et al. Association of opioids and sedatives with increased risk of in-hospital cardiopulmonary arrest from an administrative database. PLoS One 2016;11(2):e0150214.

39. Dilokthornsakul P, Moore G, Campbell JD, et al. Risk factors of prescription opioid overdose among colorado medicaid beneficiaries. J Pain 2016;17(4):436-443.

40. Dunn KM, Saunders KW, Rutter CM, et al. Opioid prescriptions for chronic pain and overdose: a cohort study. Ann Intern Med. 2010;152(2):85-92.

41. Liang Y, Turner BJ. Assessing risk for drug overdose in a national cohort: role for both daily and total opioid dose? J Pain 2015; 16(4):318325 .

42. Zedler B, Xie $\mathbf{L}$, Wang $\mathbf{L}$, et al. Development of a risk index for serious prescription opioid-induced respiratory depression or overdose in Veterans' Health Administration patients. Pain Med 2015;16(8):1566-1579.

43. Zedler B, Xie $\mathbf{L}$, Wang $\mathbf{L}$, et al. Risk factors for serious prescription opioid-related toxicity or overdose among Veterans Health Administration patients. Pain Med 2014;15(11):1911-1929.

44. Volkow ND, McLellan AT. Opioid abuse in chronic pain-misconceptions and mitigation strategies. N Engl J Med. 2016;374(13): 1253-1263.

45. Classen DC, Pestotnik SL, Evans RS, Burke JP. Computerized surveillance of adverse drug events in hospital patients. JAMA. 1991;266(20):2847-2851.

46. Schneeweiss S, Avorn J. A review of uses of health care utilization databases for epidemiologic research on therapeutics. J Clin Epidemiol 2005;58(4):323-337.

Publisher's Note Springer Nature remains neutral with regard to jurisdictional claims in published maps and institutional affiliations. 